\title{
Reducing Vulnerability and Building Resilience in the Post-Disaster Context: A Case Study of the 2006 Yogyakarta Earthquake Recovery Effort
}

\author{
Erin Joakim \\ Department of Geography and Environmental Management \\ University of Waterloo, Waterloo, Canada
}

\begin{abstract}
As the human and economic costs of natural disaster events have dramatically increased over the past three decades, governments, researchers and humanitarian agencies have increasingly focused on reducing disaster impacts and increasing the resilience of individuals, households and communities. Recent disaster recovery efforts have focused on implementing a holistic social-ecological disaster risk reduction approach popularized through post-2004 tsunami recovery programs under the mantra of 'building back better'. Although this approach has been increasingly adopted by various government and humanitarian organizations to describe their recovery and reconstruction activities, defining what is meant by 'better' and measuring 'better' as an outcome has been difficult to conceptualize and operationalize. In order to rectify this gap in the literature, the Post-Disaster Sustainable Livelihoods, Resilience and Vulnerability framework (PD-SLRV) was developed for the purposes of analyzing, evaluating and monitoring disaster recovery using the concepts of vulnerability, resilience and sustainable livelihoods.
\end{abstract}

Using the 2006 Yogyakarta, Indonesia earthquake as a case study, this paper will explore how the concepts of vulnerability, resilience and sustainable livelihoods inform the disaster recovery process, the nature of the relationship between these concepts as well as their usefulness in evaluating disaster recovery efforts. Through a detailed analysis of the various vulnerabilities and resiliencies that exist within recovering communities, the complex and dynamic nature of resilience and vulnerability is revealed, indicating a multifaceted relationship dependent on scale, context and place.

Keywords: the 2006 Yogyakarta Indonesia earthquake, disaster recovery efforts, recovery program

\section{Introduction}

On Saturday, May 27, 2006 at 5:54am local time, Yogyakarta and Central Java provinces in Indonesia were struck by a 6.3 magnitude earthquake (Resosudarmo et al., 2008; Elnashai et al., 2007). Due to the shallow depth of the earthquake, intense ground shaking was felt for almost one minute, resulting in severe damages, particularly in the districts of Bantul, Yogyakarta province and Klaten, Central Java province (BAPPENAS et al., 2006). With an estimated death toll of over 5,700 , between 40,000 - 60,000 injuries, the total destruction of over 150,000 buildings and more than 200,000 more suffering varying degrees of damage, the Yogyakarta earthquake was one of the most devastating global disasters of 2006 (BAPPENAS et al., 2006, Elnashai et al., 2007; Resosudarmo et al., 2008).

Shortly after the earthquake, there was a tremendous response from various sources, including the Indonesian government, the United Nations, the International Federation of Red Cross and Red 
Crescent Societies, international donors, as well as various other NGOs (both domestic and international). The recovery effort focused on both housing/building reconstruction as well as livelihoods rehabilitation. Over 280,000 homes were rebuilt using a community-driven approach: reconstruction funds were distributed based on the "community spirit of gotong royong, a local tradition whereby families jointly take decisions and build together” (JRF, 2007, 29). As much of the building damage was linked to poor quality construction and lack of adherence to building codes, the recovery effort focused on housing reconstruction with higher standards of safety (JRF, 2007).

Although the recovery effort is often portrayed as a successful due to the equitable distribution of relief supplies, rapid rebuilding effort and livelihoods programming, this research endeavoured to provide a more in-depth, holistic evaluation. The Post-Disaster Sustainable Livelihoods, Resilience and Vulnerability framework (PD-SLRV) incorporates a vulnerability, resilience and sustainable livelihoods perspective in order to provide further theoretical understanding of these three concepts as well as provide lessons learned and strategies for effective disaster risk reduction.

\section{Background Information}

Of the four phases of the disaster management cycle, disaster recovery has been the most poorly understood and the least well-researched (Barton, 1969; Rubin et al., 1985; Schwab, 1998; LloydJones, 2006; Chang, 2010). Disaster recovery has traditionally been defined as the longer term activities undertaken to recover from a disaster event in an attempt to return the community to predisaster norms (Mileti, 1999). On the other hand, Alesch (2004) argues that communities rarely return to pre-disaster form as "they struggle to achieve viability in the newly-emerging environment within which they exist” (3). More recent approaches, particularly after the 2004 Indian Ocean tsunami, view disaster recovery as an opportunity to achieve the goals of disaster risk reduction and contribute to improved re-development. In this sense, disaster recovery can be viewed as a catalyst for transformation and growth in the community (Kumpfer, 1999). This view is summarized in the recent mantra of disaster recovery whereby governments and non-government organizations (NGOs) claim to be 'building back better'. Although this slogan has been increasingly adopted by various government and humanitarian organizations to describe their recovery and reconstruction activities, defining what is meant by 'better' and measuring 'better' as an outcome has been difficult to conceptualize and operationalize.

In order to rectify this gap in the literature, the Post-Disaster Sustainable Livelihoods, Resilience and Vulnerability framework (PD-SLRV) was developed for the purposes of analyzing, evaluating 
and monitoring disaster recovery using the concepts of vulnerability, resilience and sustainable livelihoods. Researchers and aid organizations alike have identified the need for a systematic, independent and replicable framework and approach for monitoring, evaluating and measuring the longer-term relief and recovery operations of major disaster events (Brown et al., 2008). As vulnerability, resilience and sustainable livelihoods have been increasingly incorporated into disaster recovery theory and planning, an approach which integrates all three concepts will provide a unique opportunity to critically analyze post-disaster recovery operations. The following sections provide a brief overview of the concepts of vulnerability, resilience and sustainable livelihoods.

\section{Vulnerability}

The term vulnerability has been used in many disciplines and conceptualized in a variety of ways. Focusing specifically on the hazards literature, vulnerability has more recently been understood as a pre-existing condition, influenced by a variety of social, economic and political structures (see Cannon, Rowell \& Twigg, 2003; Blaikie et al., 1994; Hewitt, 1997; Birkmann, 2007; Pelling, 2003). From this perspective, vulnerability can be defined as "the characteristics of a person or group and their situation that influence their capacity to anticipate, cope with, resist and recover from the impact of a natural hazard” (Wisner et al., 2004:11). From this definition, vulnerability can be seen as existing before, during and after a disaster event and also incorporates aspects of resilience and coping capacity. From this perspective, some of the main factors that influence levels of vulnerability include access to various forms of tangible and intangible assets (such as social and material goods), access to knowledge and information, and access to power (Chambers, 1989; Blaikie et al., 1994; Alexander, 2000; Hewitt, 1997). Through this focus on the social, political and economic causes of vulnerability, the large-scale processes that are a reflection of power relations in a society are emphasized. While these processes reflect the structural constraints under which vulnerable households and communities must navigate during their daily activities, levels of vulnerability are also impacted by agency. The individual choices of households and communities will impact the local scale manifestations of those larger-scale processes.

A number of frameworks and models have been developed in the hazards literature to conceptualize vulnerability (i.e. PAR and Access models, BBC model, Hazards of Place). While there are areas of divergence, the main similarities that run through these different conceptualizations include: (1) exploring vulnerability from social-ecological perspective wherein both social and environmental factors are considered; (2) a focus on place and the unique ways in which larger-scale processes are manifested at the local scale; and (3) analyzing the underlying root causes of vulnerability. These three themes provide the basis for the conceptualization of vulnerability used for this research. 


\section{Resilience}

Similar to vulnerability, resilience has been conceptualized in numerous ways. Originating in the ecological literature, the first understandings viewed it as the ability to absorb the impacts of stresses, shocks and changes before a change of state occurred (Holling, 1973). In the hazards literature, resilience has commonly been perceived as the capacity to rebound, 'bounce back' or recover quickly after experiencing a disaster event (Paton, 2006; Ronan \& Johnston, 2005). While this is the common understanding of resilience, some argue that this definition is static and fails to acknowledge that communities can never return to their pre-disaster state. The experience of a disaster event creates a new physical, social and psychological landscape within the community (Paton, 2006; Alesch, 2004). More recent approaches are exploring resilience as the capacity to adapt and achieve positive transformation after a disaster event (Birkmann \& Wisner, 2006; Paton, 2006). In this sense, the disaster can be seen as a tool for promoting positive growth within the community and as having the "potential to create opportunity for doing new things, for innovation and for development” (Folke, 2006, 253; Ronan \& Johnston, 2005; Kumpfer, 1999; Kulig, 2000).

Maguire \& Hagan (2007) bring these three conceptualizations together to define resilience along three dimensions: (1) resistance: the ability to withstand or absorb external pressures and shocks; (2) recovery: the ability to return to previous levels of functioning as quickly as possible; and (3) creativity: the ability to learn, transform and increase functionality after a disaster event (see also Adger, 2000). This understanding incorporates the different conceptualizations of resilience and provides a holistic approach to explore resilience before, during and after a disaster event. Criticisms of the resilience concept argue that it has a tendency to ignore power relations and presents a de-politicized, neutral portrayal of the processes impacting disaster risk and vulnerability (Kuhlicke, 2010). Analyzing the recovery process from both a vulnerability and resilience perspective allows a focus on both the larger-scale structural processes as well as an exploration of the opportunities for moving forwards and reducing the impacts of hazards.

\section{Sustainable Livelihoods}

While vulnerability and resilience have been used in the hazards literature for many years, sustainable livelihoods (SL) has only been recently been put forth as an important concept to incorporate into the recovery period (see Cannon, Rowell \& Twigg, 2003; Arnold, 2006; Pomeroy et al., 2006; Régnier et al., 2008). While sustainable livelihoods models are more common in the development literature, the concept originated from participatory approaches to famine and food security research in the 1970s and 1980s, indicating its roots are based in hazards and hazard 
mitigation (Hussein, 2002). Chambers \& Conway (1992) provide a definition of sustainable livelihoods that has been widely used and adapted to this day:

A livelihood comprises the capabilities, assets and activities required for a means of living. A livelihood is sustainable when it can cope with and recover from stresses and shocks and maintain or enhance its capabilities and assets both now and in the future, while not undermining the natural resource base.

Livelihood activities are an important consideration during the recovery period due to their impact on levels of exposure to different hazards (through location of home and work activities), and the impact that livelihood activities can have on the environment (Abramowitz, 2001; Birkmann \& Wisner, 2006). Due to the linkages and feedbacks between livelihoods and the environment, SL approaches provide a useful link between social, economic and environmental vulnerabilities. Although SL approaches have been increasingly used by NGOs and government agencies during recovery efforts, there is a lack of conceptual models guiding efforts and experience has been limited, ad hoc in nature and success highly localized (Régnier et al., 2008). The framework developed for this research provides an opportunity to further our understanding of sustainable livelihoods initiatives during the post-disaster period.

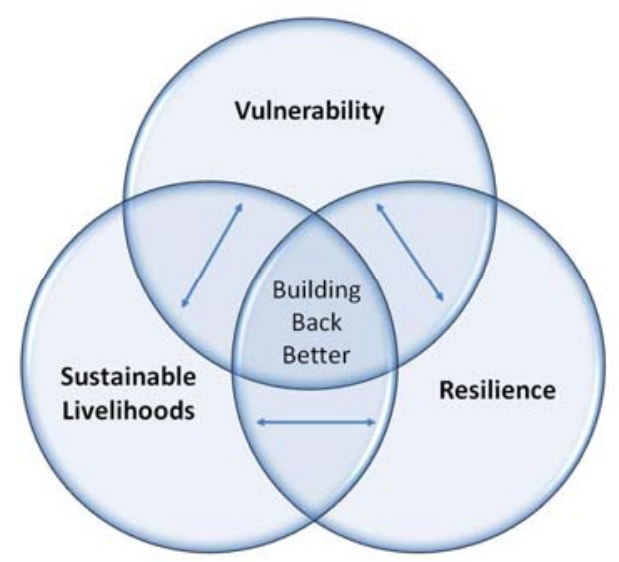

Figure 1. Post-Disaster Sustainable Livelihoods, Resilience and Vulnerability Framework (PD-SLRV)

\section{Post-Disaster Sustainable Livelihoods, Resilience and Vulnerability Framework (PD-SLRV)}

As vulnerability, resilience and sustainable livelihoods have been increasingly incorporated into disaster recovery theory and planning, an approach which integrates all three concepts will provide a unique opportunity to critically analyze post-disaster recovery operations. Using the key issues addressed in the vulnerability, resilience and sustainable livelihoods literature, there is an opportunity to holistically evaluate long-term disaster recovery initiatives and provide insight into 
these concepts and the relationships between them. A preliminary version of the PD-SLRV framework is depicted Figure 1, demonstrating the linkages between the three concepts (represented by the arrows) and the need to incorporate all three aspects in order to achieve successful disaster recovery that achieves the goal of 'building back better'.

\section{Methodology}

An in-depth case study was used to explore the disaster recovery process following the 2006 Yogyakarta, Indonesia earthquake. As the case study approach "contributes uniquely to our knowledge of individual, organization, social, and political phenomena”, this provides an ideal opportunity to explore the interactions between various small- and large-scale social, economic, political and environmental processes that create disaster events and influence disaster recovery (Yin, 2003, p. 2). This place-based approach provides an inherently geographic focus where the assessment focuses on discrete areas and places "where the risks are better understood, and can be more easily traced to pertinent processes” (Barnett, Lambert \& Fry, 2008, p. 105; 115). In this sense, the local vulnerabilities, resiliencies and livelihood strategies are placed within context of larger-scale social, economic, political and institutional processes (Fuchs, 2009). The 2006 Yogyakarta earthquake will serve as the overall 'case' used to examine and evaluate the disaster recovery process, although embedded cases (i.e. multiple impacted villages) will be used to draw out the depth and breadth of the post-disaster experience.

A total of five villages, three in Yogyakarta province and two in Central Java province, were selected to explore the recovery program and resulting conditions of vulnerability and resilience. Villages were selected based on experienced vulnerability: (1) high levels of damage (over 90\% of buildings destroyed); (2) location in earthquake zone; (3) preliminary assessment indicated varying levels of vulnerability (some communities were comprised mainly of less educated farm/construction labourers, while one was wealthier, with the majority employed as government officers with higher levels of education); and (4) varying levels of resilience (i.e. some communities attempted to self-organize and begin reconstruction and recovery independently while others waited for external assistance to come to them). In each village one focus group with community leaders was held along with a series of interviews, including approximately 25 household interviews and interviews with community leaders. Respondents were asked a series of questions regarding their perceptions and opinions on the recovery process as well as overall conditions in the community and their daily activities. 


\section{Results}

Table 1 provides an overview of the key vulnerability, resilience and sustainable livelihoods issues that were observed in each village.

Table 1. Overview of Vulnerability (VUL), Resilience (RES) and Sustainable Livelihoods (SL) Issues

\begin{tabular}{|c|c|}
\hline Village & Key Issues \\
\hline 1 & $\begin{array}{l}\text { VUL: Poor relationship with higher level government leads to lack of government } \\
\text { funding, low levels of education, lack of employment/low income, low external networks } \\
\text { among most villagers. RES: Village leader has strong connections with academia and } \\
\text { NGOs leading to funding for progressive development programs. Community has strong } \\
\text { spirit of GR. Housing rebuilding followed construction guidelines. Community has } \\
\text { increased awareness about hazards, environmental sustainability and role of education. } \\
\text { SL: Lack of job opportunities particularly for construction labourers. Strong push for } \\
\text { improving livelihood strategies through training, animal breeding, plantations and } \\
\text { tourism - need to ensure reliability and sustainability of income so not as dependent on } \\
\text { the seasons. }\end{array}$ \\
\hline 2 & $\begin{array}{l}\text { VUL: Low skill-level and education, high unemployment, older population remains in } \\
\text { community ( } 40+\text { years) as many of the younger generations have left - remaining } \\
\text { villagers have little desire to further their skills, education or start new businesses, lack of } \\
\text { awareness regarding hazards and mitigation and preparedness efforts, low external } \\
\text { networks. RES: Strong GR community spirit, strong youth organization for remaining } \\
\text { youth in the village, housing rebuilding followed construction guidelines. SL: Lack of } \\
\text { job opportunities particularly for construction labourers, low skill level, lack of initiative } \\
\text { to change occupation and receive training. }\end{array}$ \\
\hline 3 & $\begin{array}{l}\text { VUL: Social conflict in community remains high, corruption appears to be an issue, lack } \\
\text { of hazards knowledge for some villagers. RES: Population is fairly well educated with } \\
\text { strong networks outside village and province. Higher income levels as well as strong } \\
\text { religious component. Many boarding schools in village leads to strong external } \\
\text { connections, housing rebuilding followed construction guidelines. SL: Majority of } \\
\text { villagers working as government officers. }\end{array}$ \\
\hline 4 & $\begin{array}{l}\text { VUL: High psychological trauma for some victims remains, low income levels. RES: } \\
\text { Strong, outspoken community leader who pushes for funding and limiting corruption. } \\
\text { Focus on importance of education has led to many of the younger generation attending } \\
\text { university, even among poor families, housing reconstruction followed guidelines. SL: } \\
\text { Environmental degradation of rice paddies has led to severely reduced crop yields in } \\
\text { some areas. Many skilled labourers who also find jobs for unskilled members of the } \\
\text { community - strong networks within the community. Require further knowledge and } \\
\text { training for villagers regarding entrepreneurial activities. }\end{array}$ \\
\hline 5 & $\begin{array}{l}\text { VUL: Low levels of education, lack of job opportunities, limited social networks, lack of } \\
\text { awareness of hazard mitigation and preparedness. RES: Strong spirit of GR, housing } \\
\text { reconstruction followed guidelines. SL: Insect infestation related to unpredictable } \\
\text { weather and lack of dry season has destroyed crops. Lack of networks leads to low } \\
\text { employment opportunities. Many villagers lack knowledge to start/run/market their } \\
\text { businesses. }\end{array}$ \\
\hline
\end{tabular}


While many issues regarding the short- and long-term impacts of the disaster and accompanying recovery effort were found during this research, for the purposes of this paper, I will focus on the role of social networks, education and the issues associated the livelihoods.

\section{Social Networks}

Social networks examine the different formal and informal social connections (both internal and external to the community) of households and communities as well as feelings of reciprocity, trust and exchange that provide the basis for social and economic interaction and activities (DFID, 1999). In the case of the recovery effort, strong external networks were a key strategy for achieving successful disaster recovery and reducing vulnerability to future disasters. Villages with leaders and members with strong external connections were able to obtain a greater amount of goods and materials during the immediate response phase, increased funding for house reconstruction and social programming to improve overall community conditions. In some cases, particularly the poorer communities comprised mainly of construction and farming labourers, social networks were confined within the village, limiting the assistance they could provide each other since all households were impacted by the disaster.

While strong external networks increased the speed of recovery and capacity to adapt and transform after the earthquake, strong resilience was also seen in most villages through the cultural spirit of gotong royong (GR). After the earthquake, three of the villages used GR to rebuild their houses together, thereby eliminating labour costs for rebuilding. As the funding provided for house rebuilding was considered low by almost all interviewees (households in Bantul regency received 15.000.000RP while Klaten households received 20.000.000RP), this allowed the entire amount to be spent on building materials as opposed to also having to pay labour costs. Villagers also identified this community spirit of togetherness as an important aspect in providing strength and motivation to recover after the disaster. In some villages, a strict adherence to the government building deadlines meant the villagers were unable to use GR as it would have taken too long to take turns building each other's houses and they would have missed the government deadline. In these cases, the government requirements reduced the impact of this coping mechanism. In one village where the majority of villagers are employed as government officers, the use of GR was lower due to lack of construction skills among the villagers. In this case, villagers hired labourers from outside the village to rebuild their houses for them. 


\section{Education}

For the purposes of this research, education can be understood along three themes - formal education, skills, and hazards knowledge. In terms of formal education, any person who completed a university degree or diploma had obtained a reliable occupation and had the means to successfully recover after the earthquake. On the other hand, for villagers who achieved elementary to high school education, the difference in livelihood success appeared to be correlated more with skill development and the strength of social networks as opposed to levels of education. Some villagers had achieved somewhat successful livelihoods with only elementary education while others with high school lacked reliable employment and business opportunities. Those with the skills to develop an idea, the knowledge to maintain and enhance the business and the networks to market their product also achieved success in their livelihoods initiatives.

Perceptions of formal education and skill development also differed across villages. In communities and neighbourhoods where education was viewed as very important, parents were supporting their children to attend higher education institutions regardless of economic conditions (i.e. labourers were saving and finding funding sources to send their children to university). On the other hand, the poorest communities and households held less positive views towards education (i.e. while they would like to see their children attend university, they were not planning for that experience, they preferred their children to work to provide money for the household, or they held laissez-faire attitudes towards education and allowed their young children to decide what they wanted to do).

A lack of awareness regarding hazards and how to reduce vulnerability to common hazards in the area is another factor impacting levels of vulnerability and resilience. Although many villagers perceived their hazard awareness and response knowledge was adequate, other comments provided insight into this issue: many respondents felt earthquakes were caused by the old age of the earth, felt there was no need to prepare for disasters due to their belief that God would take care of them, and expressed limited preparedness actions beyond strong housing construction. Of the 125 household interviews conducted, only one interviewee expressed the need to improve the social, economic, environmental and political conditions of the area in order to reduce vulnerability to future disasters.

\section{Livelihoods}

The common livelihood issue through most villages was the lack of job opportunities. In communities where the majority of residents had obtained reliable income, economic aspects were not a major concern for the majority of villagers. Households were able to afford higher education 
and health services. On the other hand, for those residents experiencing unreliable income and lack of job opportunities, access to health and education was a concern. In terms of achieving reliable income, the connections to vulnerability and resilience were quite clear as lack of knowledge and skills, poor social networks and low initiative were identified as key aspects impacting poor livelihood outcomes. The connections between environmental conditions and livelihood outcomes was particularly evident in Klaten, where unpredictable weather, rice paddy degradation and bug infestations have severely reduced the yields for some farmers.

Two of the most common livelihood initiatives found in all villages were: (1) a program implemented by the Indonesian government focusing on training sewers and tailors and providing sewing machines as capital for business ventures; and (2) micro financing initiatives for small business enterprises. While the first program allowed some tailors to rebuild their businesses after the earthquake, the over-reliance on one skill-building technique in all communities limited the impact of this program to a few households per village. In terms of the micro-financing initiatives, accessibility for the poorest households was identified as an issue as they lacked a guarantee for the loans, lacked the education, knowledge and skills for building and maintaining a business enterprise and, in some cases, there was a lack of initiative to supplement or change their current livelihood strategies.

One important aspect of the recovery effort that could be improved is in relation to livelihood tool replacement. Many farm and construction labourers as well as small-enterprises lost their tools in the earthquake or were forced to sell off assets in order to fund the reconstruction of their houses. While there was a program to replace sewing machines, there was almost no attempt to provide funding or goods in order for households to resume their livelihood activities. In some cases, even after five years, households have been unable to save enough funds to replace items lost. This has severely limited the ability of some households to resume their livelihood activities, resulting in lower economic conditions compared to the pre-disaster context.

The earthquake disaster also had negative impacts for construction labourers, particularly in Bantul regency. Many Bantul construction labourers worked in Yogyakarta city before the earthquake, although after the recovery effort was completed they had difficulty finding employment. While the Bantul labourers were rebuilding their houses and villages after the earthquake, project leaders in Yogyakarta city began employing workers from outside the province to fill their positions. These new labourers were willing to accept lower pay and work for longer hours and so project leaders have continued to employ them, particularly for unskilled positions. The large supply of unskilled labourers has driven down the daily wage and resulted in increased unemployment for communities impacted by the earthquake. 


\section{Discussion}

While the recovery after the 2006 Yogyakarta earthquake has generally been declared successful, preliminary analysis of the data suggests that the recovery effort did not effectively address underlying issues of vulnerability, and, in fact, may have perpetuated a cycle of marginalization for the poorest members of society. Households with strong networks and businesses were able to take advantage of the programs and funding provided during the recovery period in order to rebuild and, in some cases, improve their livelihood conditions. On the other hand, the poorest villagers, mainly the farming labourers, have been excluded from participating and benefiting from these initiatives, leaving them further behind in terms of economic development.

In terms of the usefulness of the PD-SLRV framework, incorporating concepts of vulnerability, resilience and sustainable livelihoods provided an appropriate method to holistically examine the complex aspects of disaster risk and recovery. Each component added a unique perspective that allowed for a comprehensive analysis of key issues. The importance of incorporating livelihood initiatives into vulnerability reduction and recovery efforts should be emphasized. In communities and households where livelihood recovery was successful and income sources were reliable and sustainable, overall perceptions of recovery were more positive and quality of life conditions either remained similar to pre-disaster conditions or had improved. In other cases, where livelihood conditions deteriorated, the perception of the recovery effort was not as positive and quality of life conditions had declined or were stagnating. While livelihood interventions and programs are important, there is a need to focus on some of the most vulnerable populations, as current livelihood programs in Yogyakarta and Central Java province appeared to exclude some of the poorest and most vulnerable households. As well, in order for strategies to be effective, they must provide complete, long-term support: individuals, households and communities need diversified training that supports the development of knowledge regarding starting, developing, marketing and growing their businesses.

The results also demonstrate that the relationship between vulnerability and resilience is neither linear nor simple - in fact, the relationship was found to be more complex than originally anticipated. Various indicators of vulnerability can have both positive and negative feedbacks on aspects of resilience. For example, in some cases, a strong belief in God and religious faith appeared to contribute to both resilience (through increased social awareness, attempts to aid others in the community, bringing the community together, providing strength for recovery) and vulnerability (through belief that God would take care of them and thereby limiting the need for any preparedness actions to face hazards). This paradoxical relationship was seen in other areas, such as 
levels of experience and strength of government institutions. This indicates that the relationship between vulnerability and resilience is difficult to define and may be highly dependent on the context.

The importance of scale and the impact it has on understanding the concept of place was highlighted in this research. While an area can be defined as a 'place' based on the shared experience of a disaster event, this assumes that the area has some form of homogeneity. The different experiences and characteristics of each village (including livelihood strategies, government structure, village history, levels of education etc.) and even differences within villages indicates that the concept of place is not necessarily applicable to the entire area impacted by one disaster event. Although some experiences were found to be similar across all villages (i.e. the use of gotong royong as a cultural strategy for recovery, the use of pre-existing organizations to effectively control and distribute aid), the livelihood activities and problems, political and geographic conditions, community experiences and long-term recovery efforts were different for each of the five villages. This implies that places exist within places: that a true understanding of place may require a focus on various levels of scale, from the smaller-scale communities through to provincial and national levels.

\section{Conclusion}

The results reaffirm the usefulness of the PD-SLRV framework. The key components of vulnerability discussed above were found to be relevant, including a focus on place and connecting human-environment interactions. There was a strong correlation between each of the three concepts although the complexity of these relationships was highlighted, particularly for vulnerability and resilience. Incorporating aspects of vulnerability, resilience and sustainable livelihoods was useful for providing a holistic analysis of the long-term recovery effort after the 2006 Yogyakarta earthquake.

\section{Acknowledgements}

This research was carried out with the financial support of the Social Sciences Research Council of Canada (SSHRC), the International Development Research Council (IDRC) and the University of Waterloo, Canada. Support was also provided by the Tsunami and Disaster Mitigation Research Centre (TDMRC) at Syiah Kuala University, Indonesia. 


\section{References}

Abramovitz, J.N. (2001). Unnatural Disasters. Paper 158. Washington D.C.: Worldwatch Institute.

Adger, W. N. (2000). Social and Ecological Resilience: Are they Related? Progress In Human Geography, Vol. 24, pp. 347-364.

Alesch, D.J. (2004). Complex Urban Systems and Extreme Events: towards a theory of disaster recovery. $1^{\text {st }}$ International Conference of Urban Disaster Reduction. Kobe, Japan, 19 Jan 2004.

Alexander, D. (2000). Confronting Catastrophe. Hertforshire: Terra Publications.

Arnold, M. (2006). Disaster Reconstruction and Risk Management for Poverty Reduction. Journal of International Affairs. Vol. 59, no. 2, pp. 269-279.

BAPPENAS et al. (2006). Preliminary Damage and Loss Assessment: Yogyakarta and Central Java Natural Disaster. Jakarta: BAPPENAS.

Barnett et al. (2008). The Hazards of Indicators: Insights from the Environmental Vulnerability Index. Annals of the Association of American Geographers. Vol. 98, no. 1, pp. 102-119.

Barton, A. H. (1969). Communities in Disaster: A Sociological Analysis of Collective Stress Situations. Garden City, New York: Doubleday \& Company, Inc.

Birkmann, J., and Wisner, B. (2006). Measuring the Un-measurable: The Challenge of Vulnerbaility. Bonn, Germany: UNU Institute for Environment and Human Security.

Birkmann, J. (2007). Risk and vulnerability indicators at different scales: Applicability, usefulness and policy implications. Environmental Hazard. Vol. 7, no. 1, pp. 20-31.

Blaikie, P., Cannon, T., Davis, I., and Wisner, B. (1994). At Risk: Natural Hazards, People's Vulnerability and Disasters. London: Routledge.

Brown, et al. (2008). Indicators for Measuring, Monitoring and Evaluating Post-Disaster Recovery. $6^{\text {th }}$ International Workshop on Remote sensing for Disaster Applications. Available Online: http://tlc.unipv.it/6_RSDMA/Finals/4.3\%20-\%20Brown.pdf.

Cannon, T., Twigg, J., \& Rowell, J. (2003). Social Vulnerability, Sustianable Livelihoods and Disasters. Department for International Development (DFID).

Chambers, R. (1989). Vulnerability: Editorial Introduction. IDS Bulletin, Sussex, Vol. 20, no. 2.

Chambers, R., and Conway, G. (1992). Sustainable Rural Livelihoods: Practical Concepts for the 21st Century, Discussion Paper 296, Brighton: IDS.

Chang, S. E. (2010). Urban disaster recovery: a measurement framework and its application to the 1995 Kobe earthquake. Disasters, Vol. 34, no. 2, pp. 303-327.

Department for International Development (DFID). (1999). Sustainable Livelihoods Guidance Sheets. London, DFID.

Elnashai et al. (2007). The Yogyakarta Earthquake of May 27, 2006. Report No. 07-02 MidAmerica Earthquake Centre, Headquaters: University of Illinois at Urbana-Champaign.

Folke, C. (2006). Resilience: The Emergence of a Perspective for Social-Ecological Systems Analysis. Global Environmental Change, Vol. 16, no. 3, pp. 253-267.

Fuchs, S. (2009). Susceptibility versus resilience to mountain hazards in Austria - paradigms of vulnerability revisited. Natural Hazards Earth Systems Science. Vol. 9, pp. 337-352.

Hewitt, K. (1997). Regions of Risk: A Geographical Introduction to Disaster. Essex, England: Addison Wesley Longman Limited. 
Holling, C.S. (1973). Resilience and stability of ecological systems. Annual Review of Ecology and Systematics. Vol. 4, pp. 1-23.

Hussein, K. (2002). Livelihoods Approaches Compared: A Multi-Agency Review of Current Practice. London: Department for International Development (DFID).

Java Reconstruction Fund (JRF). (2007). One Year after the Java Earthquake and Tsunami: Reconstruction Achievements and the Results of the Java Reconstruction Fund. Jakarta: The World Bank.

Kuhlicke, C. (2010). Resilience: A capacity and a myth: findings from an in-depth cast study in disaster management research. Natural Hazards. Published Online: 02 November 2010.

Kulig, J.C. (2000). Community resiliency: The health potential for community health nursing theory development. Public Health Nursing. Vol. 17, no. 5, pp. 374-385.

Kumpfer, K.L. (1999). Factors and Processes Contributing to Resilience. In Glantz. M.D.; \& J.L. Johnson (Eds) Resilience and Development, Dordfecht: Kluwer.

Lloyd-Jones, T. (2006). Mind the Gap! Post-disaster reconstruction and the transition from humanitarian relief. Report for RICS by the Max Lock Centre at the University of Westminster.

Maguire, B. and Hagan, P. (2007). Disasters and Communities: Understanding Social Resilience. Australian Journal of Emergency Management, Vol. 22, pp. 16-20.

Mileti, D. (1999). Disasters by Design: A Reassessment of Natural Hazards in the United States. Washington, D.C.: Joseph Henry Press.

Paton, D. (2006). Disaster Resilience: Building Capacity to Co-Exist with Natural Hazards and their Consequences. In Eds. Paton, D. and Johnston, D. Disaster Resilience: An Integrated Approach. Springfield, Illinois: Charles C. Thomas Publisher Ltd.

Pelling, M. (2003). The Vulnerability of Cities: Natural Disasters and Social Resilience. London: Earthscan Publications.

Pomeroy et al. (2006). Coping with disaster: Rehabilitating coastal livelihoods and communities. Marine Policy. Vol. 30, pp. 786-793.

Régnier et al. (2008). From emergency relief to livelihood recovery. Disaster Prevention and Management. Vol. 17, no. 3, pp. 410-429.

Resosudarmo et al. (2008). Livelihood Recovery after Natural Disaster and the Role of Aid: The Case of the 2006 Yogyakarta Earthquake. Working Paper No. 2008/21, Australian National University.

Ronan, K.R. and Johnston, D.M. (2005). Promoting Community Resilience in Disasters: The Role for Schools, Youth and Families. New York: Springer Science+Business Media, Inc.

Rubin et al. (1985). Community Recovery from a Major Natural Disaster. Monograph \#41. Boulder: University of Colorado, Institute of Behavioral Science.

Schwab, J. (1998). Planning for Post-Disaster Recovery and Reconstruction. Planning Advisory Service Report Number 483/484. Chicago: American Planning Association.

Wisner, B., Blaikie, P., Cannon, T. and Davis, I. (2004). At Risk: Natural hazards, people's vulnerability and disasters. $2^{\text {nd }}$ Ed. London: Routledge.

Yin, R. (2003). Case Study Research: Design and Methods. Thousand Oaks, California: Sage Publications. 